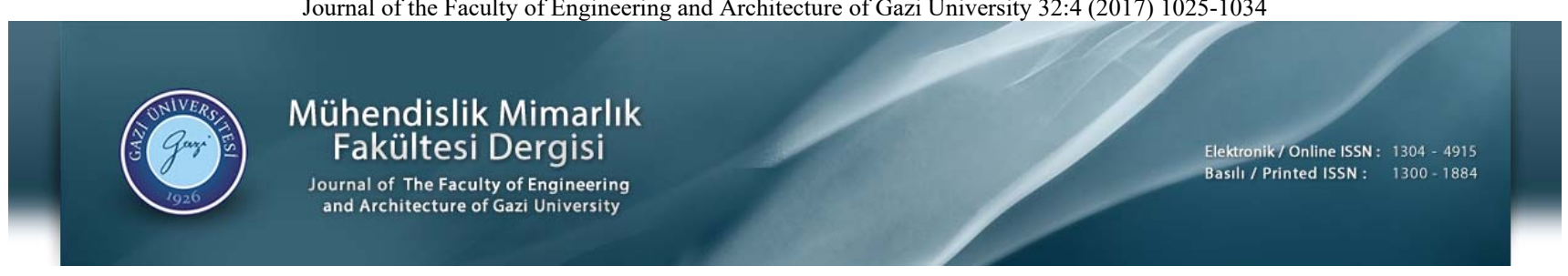

\title{
Eklem tabanlı etkili düşme tespiti
}

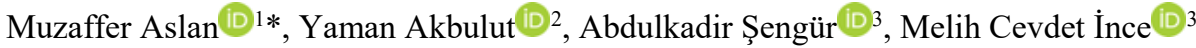 \\ ${ }^{1}$ Gazi Mesleki ve Teknik Anadolu Lisesi, Elektrik ve Elektronik Bölümü, Elazı̆̆, 23070, Türkiye \\ ${ }^{2}$ Fırat Üniversitesi Enformatik Bölümü, Bilgi İşlem Dairesi Başkanlığı, Elazı̆̆, 23119, Türkiye \\ ${ }^{3}$ Fırat Üniversitesi Teknoloji Fakültesi, Elektrik ve Elektronik Mühendisliği Bölümü, Elazığ, 23119, Türkiye
}

\section{Ö N E C I K A N L A R}

- Günlük eylemlere ait derinlik ve iskelet veri setlerinin kinect ile oluşturulması

- $\quad$ İskelet eklem özellik çıkarımı

- $\quad$ 3B iskelet verilerine dayalı yaşlı düşme tespiti

Makale Bilgileri

Geliş: 08.03.2016

Kabul: 02.07.2017

DOI:

10.17341/gazimmfd.369347

Anahtar Kelimeler:

Düşme tespiti,

kinect,

iskelet verisi,

FUKinect-fall veri seti

\section{Skeleton based efficient fall detection}

\section{H I G H L I G H T S}

- Construction of depth and skeletal datasets for daily actions with kinect

- Skeletal joint feature extraction

- $\quad$ Elderly fall detection based on 3d skeletal data

Article Info

Received: 08.03.2016

Accepted: 02.07.2017

DOI:

10.17341/gazimmfd.369347

Keywords:

Fall detection,

kinect,

skeleton data,

FUKinect-fall dataset

\section{ÖZET}

Düşme yaşlılar için ölüm ve yaralanmalarda en önemli nedenlerden biridir. Gerçek zamanlı düşme tespiti yaşlıların güvenliği için büyük önem taşımaktadır. Bu çalışmada, düşme tespiti için iskelet eklem verilerine dayalı yeni bir yöntem önerilmiştir. 21 deneğin katılımı ile oluşturulan FUKinect-Fall veri setindeki üç boyutlu (3b) iskelet verileri önce iki adet (xy ve zy) iki boyut (2b) eklem verilerine indirgenmiştir. Daha sonra seçilen referans ekleme göre iç içe geçmiş daireler üzerine kodlanmış bölgeler oluşturularak her bir eksende kalan 19 eklemin bir eylem süresince bulunduğu bölge ortalamalarını içeren özellik matrisi çıkartılmıştır. Bu özellik matrisi k-En Yakın Komşu (k-EYK) ve Destek Vektör Makinası (DVM) ile sınıflandırılmıştır. Yapılan deneysel çalışmalarda \%97,08 doğrulukta düşme tespiti yapılmıştır. 


\section{GÍRİŞ (INTRODUCTION)}

Son y1llarda, tüm dünyada yaşlı nüfus gittikçe artmaktadır. Birleşmiş Milletler tarafından 2013 yılında yayımlanan rapora göre dünyanın, 2050 yılında 65 yaş ve üzeri nüfusun 997 milyon kişi (dünya nüfusun yaklaşık \%11,6) olması beklenmektedir [1]. Benzer şekilde Türkiye'nin 2000 yıllında yaşı nüfusu yaklaşı 3,5 milyon kişi olmasına rağmen, 2050 yılında bu değerin 19,5 milyon olacağ 1 öngörülmektedir [2]. Yaşlı nüfus artışı beraberinde önemli sağlık problemlerine yol açmaktadır. Yapılan bazı çalışmalarda, 65 ve üzeri yalnız yaşayan yaşlıların \%33'nün bakıma muhtaç ve ayrıca \%63'nünde her yıl düştüğü belirtilmektedir $[3,4]$. Bu düşmeler iç doku hasarları, kemik kırılmaları ve kafa travması gibi ciddi yaralanmalara sebep olmaktadır. Bu yaralanmalar yaşlıların en önemli ölüm nedenleri olarak belirtilmektedir [5, 6]. İstatistikler 79 ve üzeri yaşlıların ölüm sebepleri sıralamasında, düşmeden kaynaklı yaralanmalardan dolayı ölümler birinci sırada, tüm yaş gruplarında ise düşmeden kaynaklı yaralanmalardan dolayı ölümler de ikinci sırada geldiği belirtilmektedir [7]. Ayrıca düşmeden kaynaklı yaralanma sonuçları hem zihinsel hem de fiziksel olarak yaşlilarda büyük hasarlara sebep olmaktadır. Görüldüğü gibi düşme özellikle yaşlılar için önemli risklere sebep olmaktadır. Buna bağlı olarak ta yaşliların yaşam kalitelerini de olumsuz etkilemektedir. Bu riskleri azaltmak için düşme tespitine duyarlı akıllı izleme sistemleri geliştirilmiştir [8]. Son yıllarda düşme tespitine yönelik çok fazla çalışma gerçekleştirilmiştir. Mevcut düşme tespit yöntemleri; giyilebilir sensör tabanlı, ortam sensör tabanlı ve görüntü tabanlı olmak üzere üç kategoriye ayrılabilir. Giyilebilir sensör tabanlı yaklaşımlar vücut konumu ve hareketini tespit etmek için sensörlerin giysiler içerisine yerleştirilmesine dayanmaktadır. Yu vd. [9] üç eksenli ivmeölçer kullanılan bir yöntem önermişlerdir. Giyilebilir sensör tabanlı yaklaşımlar da kişinin şarj etme işlemi vb. gibi durumlarda veya giyme ve çıkarma sırasında sabit bağlantılara daha fazla müdahalesi nedeni ile sensör bağlantısının kolayca kesilmesine ya da sensörün bozulmasına sebep olabilmektedir. Ayrıca giyilebilir sensör tabanlı yaklaşımlar taşıma esnasındaki rahatsızlıklardan dolayı yaşlilarda tarafından pek tercih edilmemektedir. Ortam tabanlı sensörler, titreşim verilerini hisseden, görsel ve ses veri değişikliklerine bağlı olarak çalışırlar. Alwan vd. [10] zemine yerleştirilen basınç sensör temelli bir yaklaşım önermişlerdir. Ortam tabanlı sensör yaklaşımların çoğu nesnenin yüksek basınç hassasiyeti için basınç sensörleri kullanırlar. $\mathrm{Bu}$ nedenle nesnenin tespiti ve izlenmesinde nesnenin ağırlığını dikkate alırlar. Bu yaklaşımlar yüksek maliyetli ve gözetim sistemlerinin uygulanmasında daha az müdahale sebebi ile belki tespitte daha düşük bir doğruluğa sahiptir. Çünkü sensör etrafındaki her şeyin basıncını algılamak bazen hatalı sonuçların alınmasına yol açabilmektedir. Görüntü tabanlı yaklaşımlarda, kameralara daha az müdahale ile aynı anda birden fazla olayın tespiti için kullanılabilirler. $\mathrm{Bu}$ nedenle kameralar huzur ve bakım evlerinde giderek tercih edilmişlerdir. Rougier vd. [11] düşme tespit uygulamalarında geçmiş hareket görüntüsü ve insan duruş varyasyonlarını birleştirmişlerdir. İlk görüntü tabanlı yaklaşımlarda RGB kameralar kullanılmasına rağmen, son zamanlarda popüler olan Kinect kameralar daha çok kullanılmaya başlanmıştır [12]. Feng vd. [13] çalışmalarında, bakım evlerinde yaşlıların izlenmesi ile farklı duruşları sınıflandırmak için insan siluet hareketlerini izleyerek duruş bozukluklarını tespit etmişlerdir. Bian vd. [14] ise iskelet eklemlerinin zemine olan uzaklığı ve eklem hızlarını kullanarak düşme tespiti yapmışlardır. Akagündüz vd. [15] derinlik videolarını kullanarak siluet resim yönelimlerine dayalı şekil dizi tanımlayıcı yöntem önermişlerdir. Sabit uzunluktaki siluet çerçevelerinden bir eylem videosunda ait özellik vektörü oluşturulduktan sonra kelime çantası ile kod çizelgeleri oluşturulmuş ve daha sonra Naïve Bayes sınıflandırıcı ile eylemler sınıflandırılmıştır. Ma vd. [16] Eğrilik Ölçek Uzayı (EÖU) özellikleri ve geliştirilmiş Aşırı Öğrenme Makinaları (AÖM) sınıflandırıcı kullanılarak şekil tabanlı düşme tespit yöntemi önermişlerdir. Aslan vd. [17] tarafindan EÖU özelliklerini Fisher Vektör (FV) ile kodlayarak DVM ile sınıflandırılarak geliştirilmiştir. Diğer bir çalışmada, derinlik kamerası sahte düşme pozların tespit için tavana monte edilmiştir [18]. Tespit edilen insan vücut alanı ve önemli şekil uzunlukları gibi özellikler k-NN sınıflandırıcı ile düşme tespiti ve günlük eylemlerin sınıflandırmışlardır. Dobis vd. [19] çalışmalarında düşme tespiti için başka RGB-D sensör tabanlı basit fakat sağlam bir yaklaşım önermektedirler. Yöntem temel olarak deneğin kütle merkezini izlemektedir. Bu çalışmada Saklı Markov Model (SMM) izlenen vücut şekli, kütle merkezinin hızı ve kütle merkezi pozisyonun gözlemleri ile düşme tespiti yapmışlardır. İskelet eklem özellikleri kullanılan başka iskelet tabanlı düşme tespit sistemi Zhang ve Tian [20] tarafindan önerilmiştir. Araştırmacılar özellikler olarak yapı-hareket-tabanlı iskelet istatistikleri serisini incelemişlerdir. Görüntü ve derinlik tabanlı özelliklerin daha da geliştirilmesi için bir araya getirmişlerdir. $\mathrm{Bu}$ çalışmada; Kinect kullanarak 21 deneğe ait insan vücudunun 3B iskelet verileri çıkartılmıştır. Düşme tespiti için bu iskelet verilerinin kullanıldı ğı bir yöntem önerilmiştir. Yöntemde, 3B iskelet verisinin $\mathrm{xy}$ ve $\mathrm{zy}$ koordinat eksenleri üzerine oturtulmuş ve kalça eklemini referans alarak, tüm iskeleti kapsayacak şekilde iç içe geçmiş daireler üzerinde kodlanmış bölgeler ile bir eylem boyunca bir eklemin bütün çerçevelerdeki ortalamalarından oluşan öznitelik matrisi elde edilir [21]. Öznitelik matrisi DVM ve k-EYK sınıflandırma yöntemleri kullanılarak düşme tespiti ile birlikte günlük eylemler de tespit edilmiştir.

\section{YÖNTEM (METHOD)}

\section{1. İskelet Eklemlerinden Öznitelik Çıkarılması (Feature Extraction from Skeletal Joints)}

Microsoft Yazılım Geliştirme Kiti (MYGK) derinlik görüntülerini işleyerek eklem pozisyonlarını tanımlamaktadır. MYGK ilk önce derinlik görüntülerindeki bir piksel için belirlenen eklem pozisyonunu tahmin etmekte ve her piksel için doğruluk düzeyini hesaplamaktadır. 
Bundan sonra doğruluk düzeyleri ile verilen iskelet etiketlerinden iskeleti seçmektedir [22]. Kinect' in insan iskeleti için oluşturduğu iskelet modeli Şekil 1'de gösterilmiştir.

Vücudun $\mathrm{K}$ tane eklemle temsil edildiği $\mathrm{T}$ adet çerçeveden oluşan bir eylemde herhangi bir çerçevedeki (ti) ve herhangi bir eklemin (k) $\mathrm{x}, \mathrm{y}$ ve $\mathrm{z}$ koordinatları $x_{k}^{(t)}, y_{k}^{(t)}, z_{k}^{(t)}$ şeklindedir [21]. Böylece; 20 eklemin üç eksene ait eklem vektörü;

$E=\left[x_{1}^{(t)}, y_{1}^{(t)}, z_{1}^{(t)}, x_{2}^{(t)}, y_{2}^{(t)}, z_{2}^{(t)}, \ldots, x_{K}^{(t)}, y_{K}^{(t)}, z_{K}^{(t)}\right]$

şeklindedir.

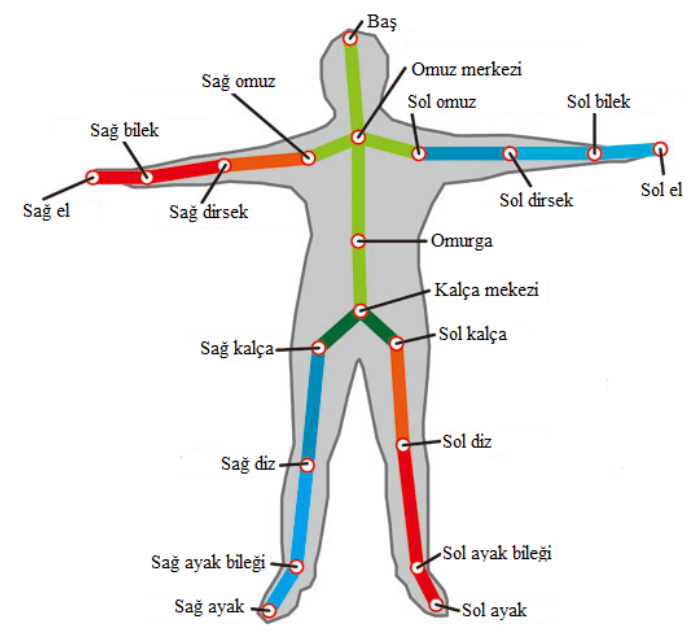

Şekil 1. Kinect iskelet eklem yapısı

(Kinect skeletal joint structure) [22]

Eylem tanıma için 3B eklem koordinatları, iki adet ( $x y$ ve zy) 2B eklem koordinatlarına indirgenmesine dayalı bir model oluşturulmuştur [23, 24] Seçilen $x y$ ve $z y$ eksenleri için $30^{\circ}$ 'lik açı ile oluşturulan model ve modeldeki bölgeler Şekil 2'de gösterilmiştir. Shotton yöntemine göre, eklem noktalarından kalça merkezi eklemi referans alınmıştır [25, 26]. Bu şekilde ölçekten bağımsız bir poz elde edilmiştir. Eklem vektörü referans ekleme göre düzenlenirse Eş. 1 şeklinde yazılabilir.
$E=\left[0,0,0, x_{2}-x_{1}, y_{2}-y_{1}, z_{2}-z_{1}, \ldots, x_{K}-x_{1}, y_{K}-\right.$

$\left.y_{1}, z_{K}-z_{1}\right]$

Her bir eklemin referans ekleme göre açısı $\left(\alpha_{i}\right)$ ve uzaklığ 1 $\left(u_{i}\right)$ sirasıyla Eş. 2 ve Eş. 3 'te verilmiştir [26].

$\alpha_{i}=\arctan \frac{y_{i}-y_{1}}{x_{i}-x_{1}}$

$u_{i}=\sqrt{\left(x_{i}-x_{1}\right)^{2}+\left(y_{i}-y_{1}\right)^{2}}$

Ayrıca $R_{x y}=u_{\max }$ ve $r_{x y}=\frac{R}{2}=\frac{u_{\max }}{2}$ bağıntıları yardımla hesaplanabilir [21]. Seçilen $x y$ eksenine göre bir çerçevedeki eklem açılar için $A_{x y}=\left[0, \alpha_{2}, \alpha_{3}, \alpha_{4}, \ldots, \alpha_{K}\right]$ ve bütün eklemlerin referans ekleme olan uzaklığı $U_{x y}=$ $\left[0, u_{2}, u_{3}, u_{4} \ldots, u_{K}\right]$ vektörleri olarak yazılabilir. Aynı işlemler $y z$ ekseni için de yapılarak $A_{z y}$ ve $U_{z y}$ vektörleri yazılabilir [21].

Eksenler belirli $\theta$ açısı ile bölgelere ayırıldığında oluşacak bölge sayısı $n_{b}=2 \times(360 / \theta)$ ile hesaplanabilir [23, 26]. Bir çerçevede eklemlerin referans ekleme olan uzaklığ 1 ve açısına bağlı olarak hangi bölgede bulunduğu tespit edilir. Buna göre eklemlerin bulunduğu bölge vektörü $B_{x y}=$ $\left[0, b_{2}, b_{3}, b_{4}, \ldots, b_{K}\right]$ şeklinde yazılabilir. Aynı işlemler $z y$ ekseni içinde yapılarak $B_{z y}$ vektörü elde edilir. Böylece tüm çerçevelerdeki her bir eklem için $B_{x y}$ ve $B_{z y}$ matrisleri elde edilir [21]. Bu şekilde referans eklem dışındaki 19 eklemin, her bir çerçevedeki konum bilgisi, hangi bölgede olduğu belirlenmiş olunur. Bir hareket ya da eylem boyunca bir eklemin bütün çerçevelerdeki ortalamasının alınması ile öznitelik matrisi elde edilir.

Öznitelik matrisi oluşturmak için bir eylemde bir eklemin tüm çerçevelerdeki ortalaması alınmaktadır. Aynı zamanda bu ortalama tanımlayıcı olarak ifade edilebilmektedir. Her iki eksen için de bu yöntem ile öznitelik matrisi oluşturulduğunda eylemlere ait zamansal bilginin kaybolduğu görülmüştür. $\mathrm{Bu}$ durum birbirinin tersi olan eylemlerin karıştırılmasına sebep olmaktadır. Bu sorunun çözümü için zamansal hiyerarşik yapı kullanılmıştır [27]. Bir eylemdeki $\mathrm{T}$ adet çerçeve için zamansal hiyerarşik yapı Şekil 3 'te görülmektedir. Önce çerçevelerin hepsi $\mathrm{t}=1$ 'den $\mathrm{T}$ 'ye

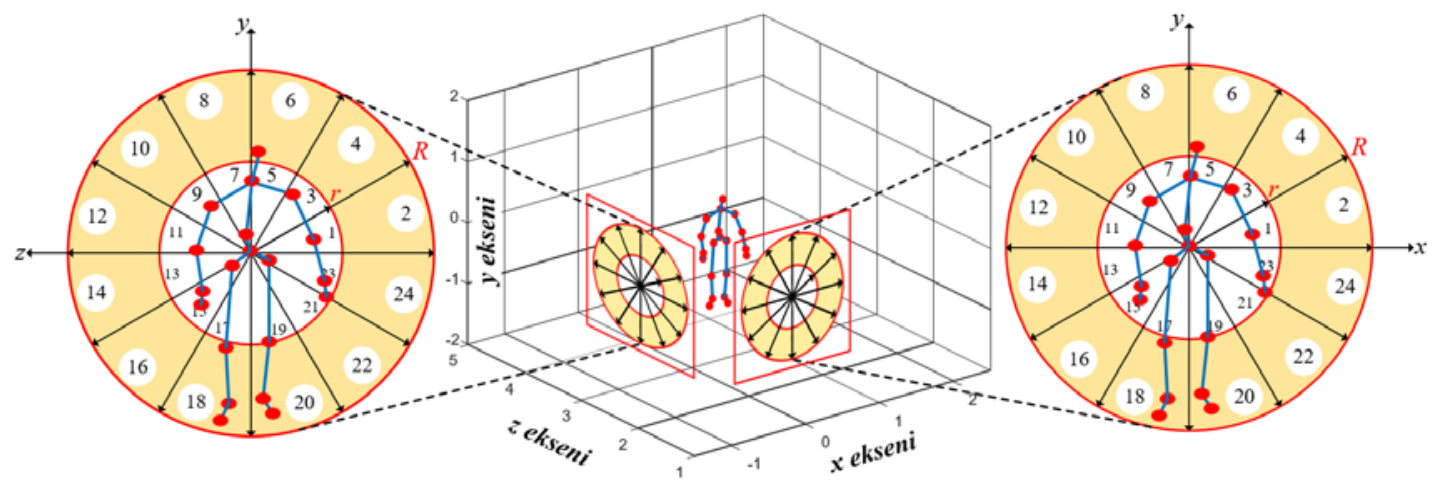

Şekil 2. 2B eksen modeli ve bölgeleri (2D axis model and regions) 
(O1) sonra siralı olarak t=1'den $T / 2$ 'ye (O2), $T$ /4 'ten 3T /4'e (O3) ve son olarak $T / 2$ 'den T'ye (O4) kadar olan çerçevelerin her eklem için ortalaması alınarak öznitelikler oluşturulmuştur. Böylece öznitelik sayısını 4 katına çıkartılmıştır.

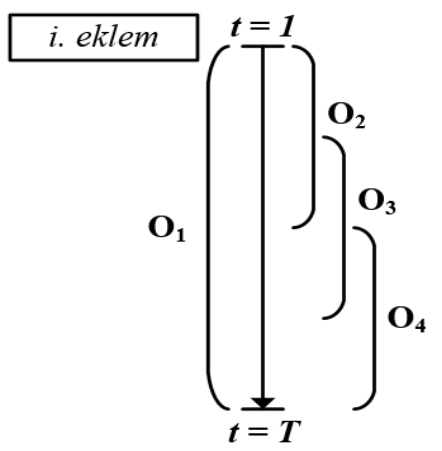

Şekil 3. Ortalama tanımlayıcının zamansal hiyerarşik yapısı [27] (Temporal hierarchical structure of mean descriptor)

\subsection{Sinıflandırma (Classification)}

Bu bölümde, son dönemlerde Aşırı Öğrenme Makinaları (ELM) , DVM, k-EYK ve Bayes gibi veri sinıflandırılmasında yaygın olarak kullanılan $[28,29]$ DVM ve k-EYK sınıflandırıcılar kullanılacaktır.

\subsection{1. k-En yakın komşu algoritması}

(k-Nearest neighbor algorithm)

En klasik örüntü tanıma yöntemlerinden biridir. Sınıfların olasılık dağılımlarına ihtiyaç duyulmadan sınıflandırma yapılmasını sağlayan örüntü sinıflandırıcıdır. Sınıflandırmayı k değerine bağlı olarak yapmaktadır. Test edilecek veri, eğitim kümesindeki verilerin her birine olan uzaklığını hesapladıktan sonra sınıfı bilinen en yakın komşuların $\mathrm{k}$ tanesi olarak seçilir. Daha sonra eğitim verilerinden kendisine en yakın olana atanır [29]. Uzaklık hesaplamasında çoğunlukla Oklid $\sqrt{\sum_{i=1}^{k}\left(x_{i}-y_{i}\right)^{2}}$ yöntemi kullanılmakla birlikte Minkowski $\left(\sum_{i=1}^{k}\left(\left|x_{i}-y_{i}\right|\right)^{q}\right)^{1 / q}$ ve Manhattan $\sum_{i=1}^{k}\left|x_{i}-y_{i}\right|$ yöntemleri de kullanılabilmektedir [29].

\subsubsection{Destek vektör makinesi (Support vector machine)}

DVM örüntü tanımada popüler olan bir yöntemdir. DVM algoritmaları başlangıçta iki sınıflı doğrusal verilerin sınıflandırılması için tasarlanmış olmakla birlikte daha sonra hem daha çok sınıflı hem de doğrusal olmayan veri sınıflandırmaları içinde kullanılmaya başlanmıştır. Temel çalışma prensibi iki sınıflı veriye ait bir kümeyi ayıran ve en iyi hiper düzlemin bulunmasına dayanmaktadır [30]. Temel çalışma prensibi, $\{-1,+1\}$ şeklinde sınıf etiketleri ile gösterilen iki sınıftaki örneklerin eğitim verilerinden elde edilen karar fonksiyonunu kullanarak eğitim verilerini ayıran en iyi hiper düzlemin bulunmasına dayanmaktadır [31]. Fakat iki sınıflı verileri ayırabilecek birçok hiper düzlem olmakla birlikte DVM Şekil 4'de görüldüğü gibi kendisine yakın noktalar arasındaki uzaklığı maksimum yapacak hiper düzlemi bulabilmesidir.

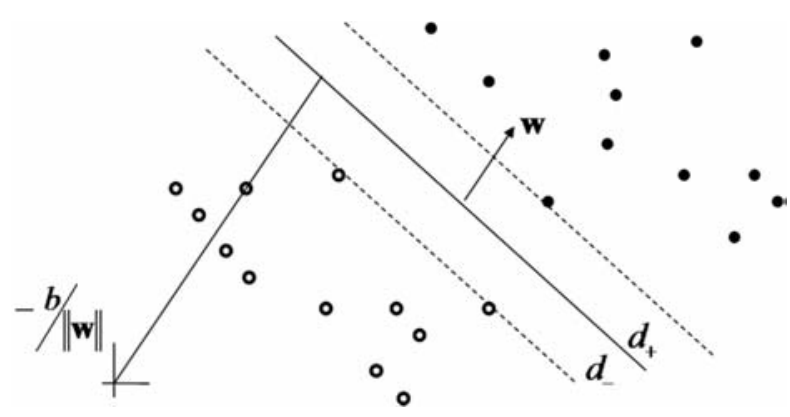

Şekil 4. En iyi hiper düzlem ve marjları

(Best hyperplane and margins)

DVM'nin $l$ sayıda örnekten oluşan $\left(x_{i}, y_{i}\right), i=1, \ldots, l$ biçiminde eğitim verisinin olduğunu kabul edelim. Burada $x_{i} \in R^{N} \mathrm{~N}$ boyutlu uzayı ve $y_{i} \in\{-1,+1\}$ sinıf etiketlerini göstermektedir. Buna göre sinıflandırmanın amacı olan karar fonksiyonu Eş. 4'teki gibi yazılabilir [31].

$y=f(x)=\operatorname{sgn}(\langle w, x\rangle+b)$

Burada $x$ herhangi bir girişin sınıf etiketini, $w$ ağırlık vektörünü ve $b$ ise eğilim değerini tanımlamaktadır.

\section{DENEYSEL ÇALIŞMALAR (EXPERIMENTAL WORKS)}

Bu bölümde, önerilen yöntemin test edilmesi için FUKinectFall ve UTKinect-Action veri setleri kullanılmıştır. Deneysel sonuçlar bölümünde sonuçların değerlendirilmesi yapılmıştır.

\subsection{FUKinect-Fall Veri Setinin Oluşturulması (Construction of FUKinect-Fall Dataset)}

FUKinect-Fall veri seti Kinect V1 kullanılarak oluşturulmuştur. Veri setini oluşturabilmek için Kinect kamera yerden $95 \mathrm{~cm}$ yükseklikte tripot üzerine yerleştirildi. Kinect'in görme sinırları olan $0,5 \mathrm{~m}$ ile $4,5 \mathrm{~m}$ referans alınarak $4 \times 4$ m'lik bir alan ve derinlik sensörünün dikey, yatay görüş açıları dikkate alınarak Şekil 5 'teki veri seti alanı oluşturuldu.

Ayrıca veri setinin oluşturulmasındaki deneklerin boy, kilo gibi fiziksel özellikleri ve yapılan eylem türüne bağlı olarak eylemler $2 \mathrm{~m}$ ile 3,5 m arasındaki alanında gerçekleştirildi. Şekil 6'da ise bu eylemlerin gerçekleştirildiği çalışma alanı görülmektedir. Veri seti, 19-72 yaş arasındaki 21 denek tarafından gerçekleştirilen yürüme, eğilme, oturma, çömelme, uzanma ve düşme eylemlerini içermektedir. Her bir eylem Şekil 7'deki eylem sırasına göre 8'er kez tekrar edildi. Şekil 7'de görüldüğü gibi 1-4, 2-3, 5-6 numaralı eylemler karşılık olarak ve 7-8 numaralı eylemlerin başlangıç noktası aynı olmasına rağmen orta alandan sonra zit yönlere doğru devam ettirilmektedir. 


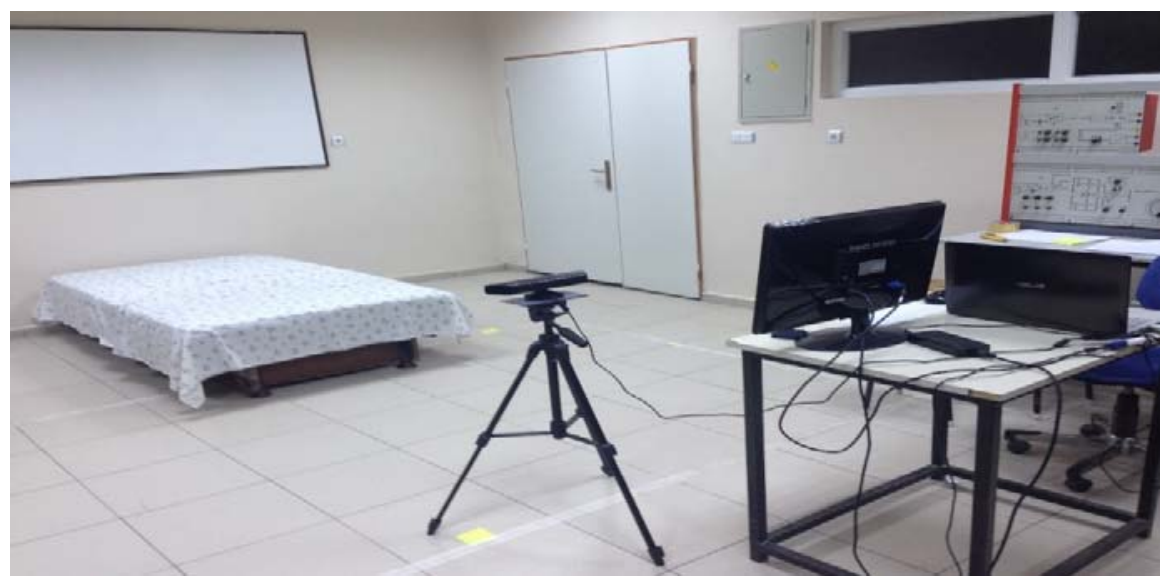

Şekil 5. Deneysel veri seti toplama alanı (Experimental Dataset collection environment)

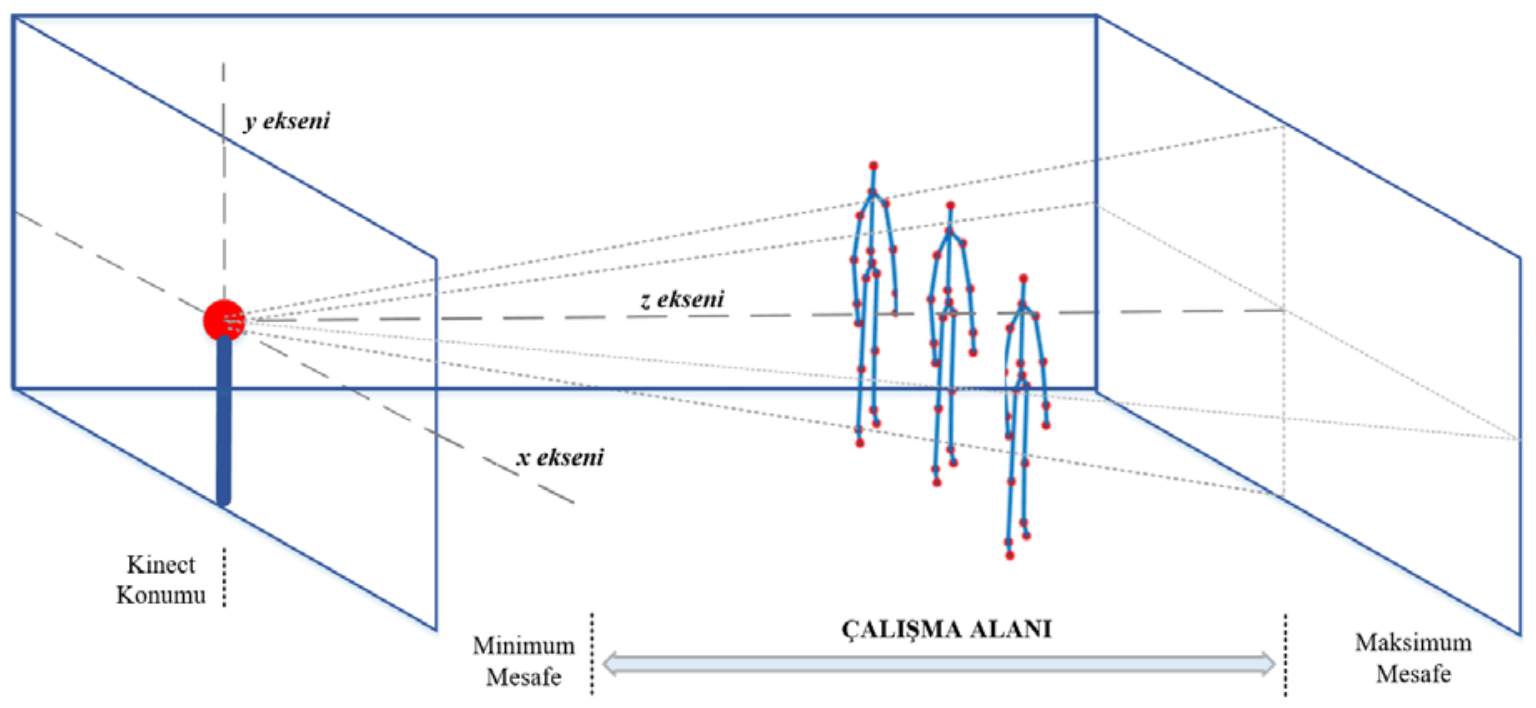

Şekil 6. Veri seti toplama çalışma alanı (Dataset collection work environment)

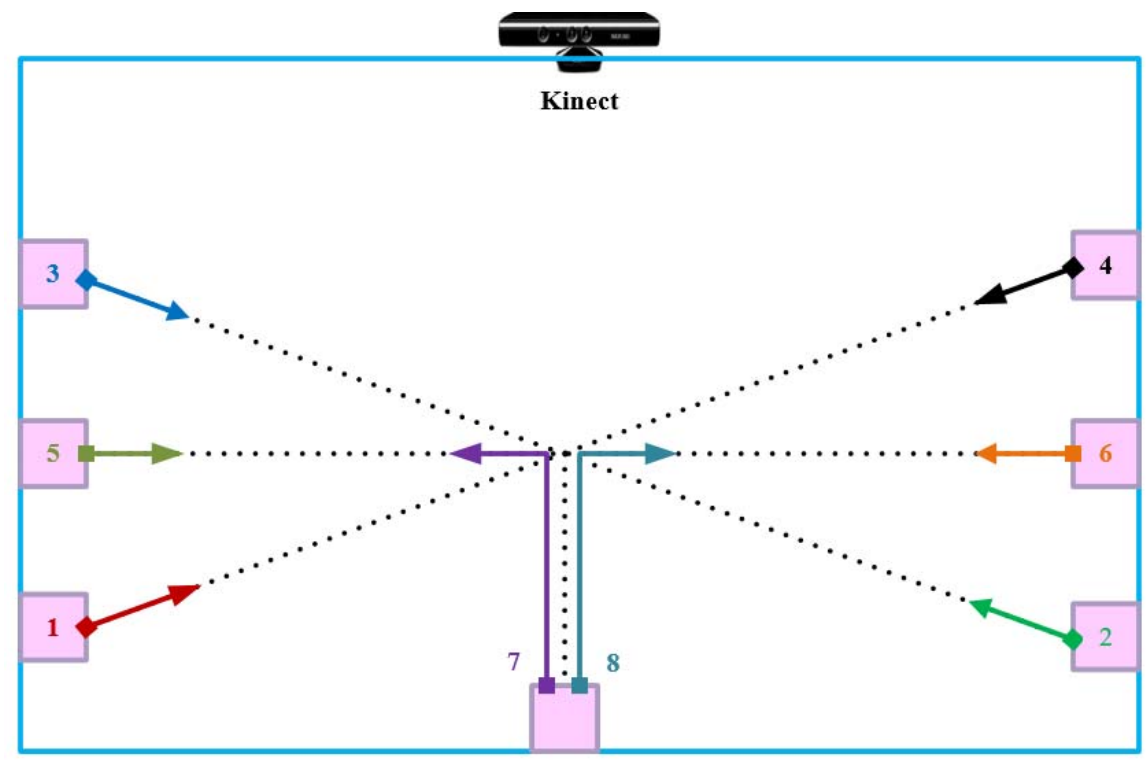

Şekil 7. Veri seti eylem yönleri (Dataset action directions) 
Toplamda (6 eylem $\times 8$ tekrar $\times 21$ denek) 1008 derinlik videosu ve 20 eklemin 3B koordinatları $(x, y, z)$ kaydedildi. Her bir video süresi eylem özelliğine bağlı olarak yaklaşık 45 saniye, $320 \times 240$ çözünürlükte ve saniyede 30 çerçeve olarak kaydedildi. Bu çalışmada elde edilen yürüme, eğilme, oturma, çömelme, uzanma ve düşme eylemelerine ait bazı iskelet ve siluet görüntüleri Şekil 8'de görülmektedir.

\subsection{Deneysel Sonuçlar (Experimental Results)}

Deneysel çalışmalarda, FUKinect-Fall ve UTKinect-Action [31] veri setleri kullanıldı. FUKinect-Fall ile yapılan deneysel çalışmalarda Şekil 2'de önerilen iskelet modeline göre $5^{\circ}, 10^{\circ}, 30^{\circ}$ ve $45^{\circ}$ lik açılar ile sirasiyla $2 \times\left(360^{\circ} / 5^{\circ}\right)=144,72,24$ ve 16 bölgelere ayrıld1. Her bölge açısı için ayrı ayrı öznitelik matrisi oluşturuldu. Eylemlerin sınıflandırılması için 19 eklem $\times 4$ zamansal yap $1 \times 2$ eksen olmak üzere toplam 152 öznitelik k-EYK ve DVM sinıflandirıciların girdi katmanına uygulandı.

İlk olarak önerilen yöntem ile 6 eylemin sınıflandırılması gerçekleştirildi. Ayrıca 6 eylemin sınıflandırmasında üç ayrı uygulama gerçekleştirildi. Birinci uygulamada özniteliklerin $\% 50$ 'si eğitim, diğer \%50'si de test için kullanıldı. İkinci uygulamada verilerin $\% 75$ 'i eğitim ve $\% 25$ 'i test için ve üçüncü uygulamada ise verilerin \%90 eğitim ve \%10'u test için kullanılmıştır. Yapılan deneysel çalışmalarda k-EYK ve DVM algoritmaları ile 6 eylemin sınıflandırılma sonuçları Tablo 1 ve Tablo 2'de görülmektedir.
Tablo 1. k-EYK ile 6 eylemin sınıflandırılma sonuçları (Classification results of 6 actions with k-NN)

\begin{tabular}{lllll}
\hline Bölge açis1 & $\mathrm{k}$ & 1. & 2. & 3. \\
& & Uygulama & Uygulama & Uygulama \\
\hline \multirow{4}{*}{$5^{\circ}$} & 1 & 88,13 & 88,75 & 90,63 \\
& 3 & 88,96 & 90,00 & 90,63 \\
& 5 & 87,29 & 91,25 & 91,67 \\
& 7 & 88,54 & 91,25 & 89,58 \\
& 9 & 87,08 & 90,83 & 91,67 \\
$10^{\circ}$ & 11 & 88,33 & 90,83 & 90,63 \\
\hline & 1 & 88,13 & 88,33 & 88,54 \\
& 3 & 90,00 & 90,83 & 88,54 \\
& 5 & 90,63 & 91,67 & 91,67 \\
$30^{\circ}$ & 7 & 89,38 & 92,50 & 91,67 \\
& 9 & 88,33 & 92,08 & 91,67 \\
& 11 & 87,71 & 91,67 & 92,71 \\
\hline & 1 & 82,29 & 84,17 & 86,46 \\
& 3 & 83,75 & 85,00 & 88,54 \\
& 5 & 85,83 & 87,08 & 85,42 \\
& 7 & 85,42 & 85,42 & 90,63 \\
& 9 & 83,96 & 85,42 & 87,50 \\
& 11 & 83,33 & 86,67 & 87,50 \\
\hline & 1 & 85,21 & 86,67 & 91,67 \\
& 3 & 87,29 & 89,58 & 83,33 \\
& 5 & 87,08 & 88,75 & 84,38 \\
& 7 & 87,71 & 88,75 & 86,46 \\
& 9 & 87,08 & 89,17 & 86,46 \\
& 11 & 86,04 & 87,92 & 88,38 \\
\hline
\end{tabular}

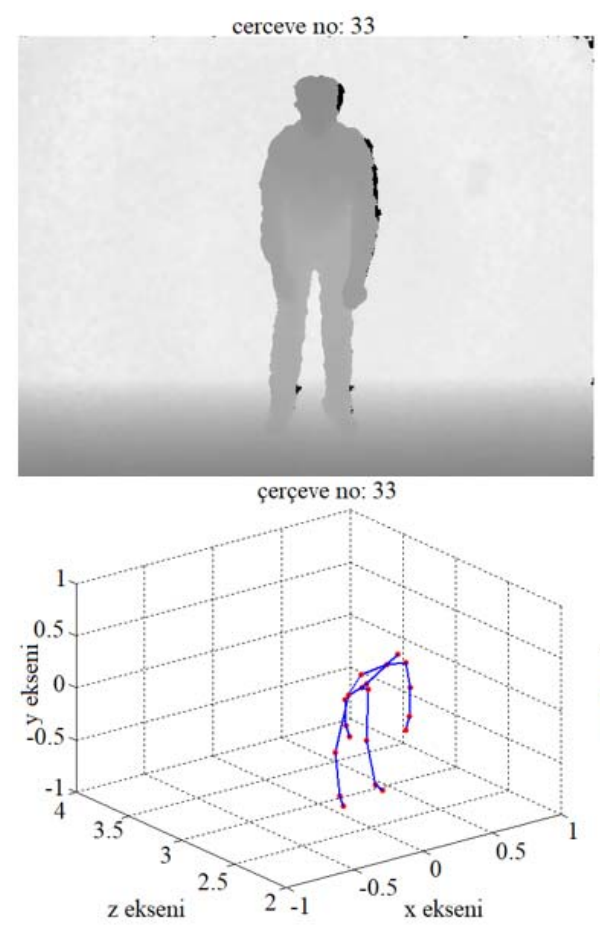

(a)

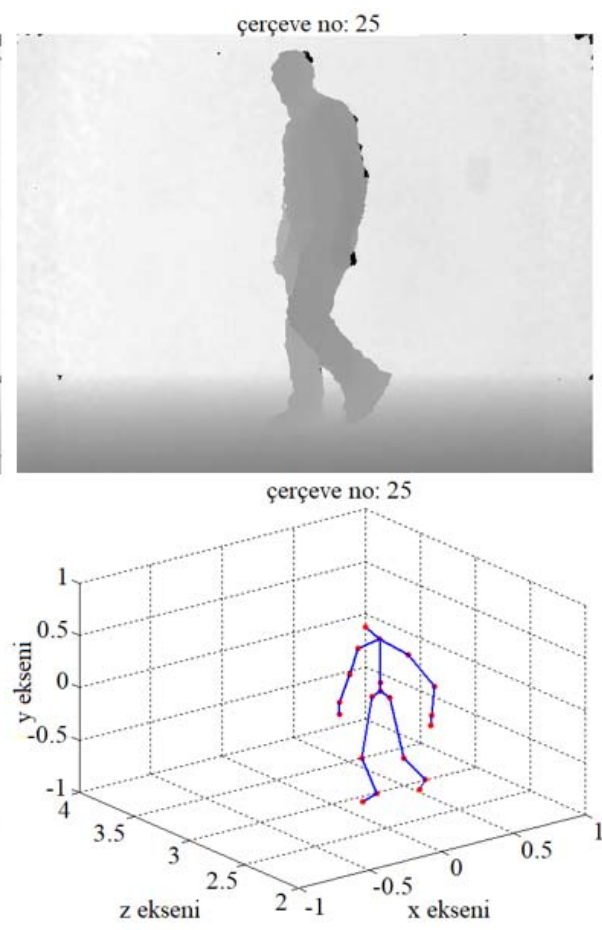

(b)

Şekil 8. Veri setine ait bazı eylemlerin derinlik ve iskelet görüntüleri a) Eğilme b) Yürüme (Depth and skeleton illustrations of some actions of the dataset a) Bending b) Walking) 
Tablo 1'de görüldüğü gibi üç uygulamada da k-EYK için en iyi sınıflandırma başarımı10 'lik bölge açısı ile elde edilmiştir. Birinci uygulamada $\mathrm{k}=5$ için \%90,63 doğrulukta, ikinci uygulamada $\mathrm{k}=7$ için bu değer $\% 92,50$ ve üçüncü uygulamada ise $\mathrm{k}=11$ için $\% 92,71$ doğrulukta eylem sınıflandırması yapılmıştır.

DVM ile yapılan deneysel çalışmalarda, yükssek başarım elde etmek için en uygun DVM parametrelerinin seçilmesi gerekmektedir. Bu bağlamda literatürde en çok kullanılan 10-katlı çapraz geçerlilik testi uygulanmıştır. 10-katlı çapraz geçerlilik testi sonuçlarına göre deneysel çalışmalarda, düzenleme parametresi $\mathrm{C}=200$, kernel fonksiyonu için radyal tabanlı fonksiyon ve fonksiyonun sigma değeri ise 15 olarak belirlenmiştir.

Tablo 2. DVM ile 6 eylemin sınıflandırılma sonuçları (Classification results of 6 actions with SVM)

\begin{tabular}{llll}
\hline Bölge açısı & 1. Uygulama & 2. Uygulama & 3. Uygulama \\
\hline $5^{\circ}$ & 84,79 & 88,75 & 93,75 \\
$10^{\circ}$ & 84,38 & 89,17 & 92,71 \\
$30^{\circ}$ & 82,79 & 87,92 & 90,63 \\
$45^{\circ}$ & 84,38 & 88,75 & 89,58 \\
\hline
\end{tabular}

Benzer şekilde DVM ile yapılan sınıflandırma sonuçları incelendiğinde bölge açısının azalması ile hassasiyetin arttığ görülmektedir. Böylece, birinci uygulama için \%84,79, ikinci uygulama için \%88,75 ve üçüncü uygulama için de \%93,75 doğru sınıflandırma başarımları elde edilmiştir.

Ayrıca önerilen yöntemin başarımı 10-katlı çapraz geçerlilik analizi ile test edilmiştir. Bu bağlamda, birinci uygulamada
k-EYK yöntemi için bölge açısı $5^{\circ}$ ve $k=7$ seçilmiştir ayrıca ikinci uygulamada ise DVM yöntemi için yine bölge aç1s $15^{\circ}$, radyal tabanlı fonksiyon ve sigma değeri 15 seçilerek ilgili deneyler yapılarak sonuçlar sırası ile Tablo 3 ve 4'de gösterilmiştir. Tablo 3 'teki sonuçlardan görüldüğü üzere uzanma eylemi \%20,62 oranında hatalı şekilde düşme eylemi olarak sınıflandırmıştır. En kötü sınıflandırma oranı \% 75,62 ile uzanma eyleminde görülürken ve en başarılı sınıflandırma oranı $\% 98,12$ ile yürüme eyleminde kaydedilmiştir.

DVM sonuçlarını gösteren Tablo 4'de, en çok oturma ve çömelme eylemlerinin düşme eylemi ile karıştırıldığ1 görülmektedir. Diğer bir ifade ile oturma eyleminin ortalama $\% 4,37$ si ve çömelme eyleminin ortalama $\% 3,75$ 'i düşme eylemi olarak tanınmıştır. Ayrıca en yüksek doğru sinıflandırılan $(\% 96,25)$ eylem yürüme eylemi olurken, en düşük doğru sınıflandırma başarımı $(\% 78,75)$ uzanma eylemi için elde edilmiştir. Uzanma eylemi en çok düşme eylemi ile karıştırılmıştır.

Aslında bu çalışmada daha önemli olan düşme ve düşmenin olmadığı durumların ayırt edilmesidir. Yine burada da 6 eylemin sınıflandırılmasında olduğu gibi üç ayrı uygulama gerçekleştirildi. k-EYK ve DVM ile yapılan deneysel çalışma sonuçları sırası ile Tablo 5 ve Tablo 6'da verilmiştir.

Tablo 5'teki sonuçlar incelendiğinde yapılan tüm deneysel çalışmalarda birinci uygulama için $5^{\circ}$ lik bölge açısında \%95 doğrulukta sınıflandırma, ikinci uygulamada en iyi $45^{\circ}$ lik bölge açısında \%96,25 doğrulukta sınıflandırma ve üçüncü uygulamada ise $10^{\circ}$ 'lik bölge açısında \%96,88 doğrulukta sinıflandırma elde edilmiştir.

Tablo 3. k-EYK metodu ve 10-katlı çapraz geçerlilik testi ile elde edilen karışıklık matrisi (Confusion matrix obtained by the k-NN method and the 10-fold cross-validation test)

\begin{tabular}{lllllll}
\hline Gerçek & Tahmin & \multicolumn{5}{l}{} \\
\cline { 2 - 6 } & Düşme & Eğilme & Uzanma & Oturma & Çömelme & Yürüme \\
Düşme & 77,50 & 5,62 & 12,50 & 0,63 & 2,50 & 1,25 \\
Eğilme & 0,00 & 91,25 & 0,00 & 1,25 & 1,87 & 5,63 \\
Uzanma & 20,62 & 1,88 & 75,62 & 1,88 & 0,00 & 0,00 \\
Oturma & 0,00 & 1,88 & 0,00 & 91,87 & 3,12 & 3,13 \\
Çömelme & 0,63 & 9,37 & 0,00 & 7,50 & 78,12 & 4,38 \\
Yürüme & 0,00 & 1,25 & 0,00 & 0,00 & 0,63 & 98,12 \\
\hline
\end{tabular}

Tablo 4. DVM metodu ve 10-katlı çapraz geçerlilik testi ile elde edilen karışıklık matrisi (Confusion matrix obtained by SVM method and 10-fold cross-validation test)

\begin{tabular}{lllllll}
\hline Gerçek & Tahmin & & & & \\
\cline { 2 - 6 } & Düşme & Eğilme & Uzanma & Oturma & Çömelme & Yürüme \\
Düşme & 83,13 & 1,25 & 9,37 & 0,00 & 1,88 & 4,37 \\
Eğilme & 0,00 & 92,5 & 0,00 & 0,00 & 0,63 & 0,62 \\
Uzanma & 1,88 & 15,00 & 78,75 & 0,63 & 1,88 & 4,37 \\
Oturma & 4,37 & 0,00 & 0,63 & 88,13 & 2,50 & 4,37 \\
Çömelme & 3,75 & 0,00 & 0,00 & 5,00 & 84,37 & 6,88 \\
Yürüme & 3,12 & 0,00 & 0,00 & 0,00 & 0,63 & 96,25 \\
\hline
\end{tabular}


Tablo 5. k-EYK ile düşme ve düşme olmayan eylemlerin sınıflandırılma sonuçları (Classification results of non-falling and falling actions with k-NN)

\begin{tabular}{|c|c|c|c|c|}
\hline Bölge aç1s1 & $\mathrm{k}$ & 1. Uygulama & 2.Uygulama & 3.Uygulama \\
\hline \multirow{6}{*}{$5^{\circ}$} & 1 & 94,38 & 94,17 & 94,79 \\
\hline & 3 & 93,33 & 93,75 & 95,83 \\
\hline & 5 & 92,50 & 91,67 & 93,75 \\
\hline & 7 & 95,00 & 95,00 & 94,79 \\
\hline & 9 & 93,13 & 93,75 & 92,71 \\
\hline & 11 & 90,83 & 92,08 & 91,67 \\
\hline \multirow{6}{*}{$10^{\circ}$} & 1 & 93,54 & 93,33 & 96,88 \\
\hline & 3 & 92,50 & 95,00 & 95,83 \\
\hline & 5 & 91,88 & 95,00 & 94,79 \\
\hline & 7 & 92,92 & 93,33 & 94,79 \\
\hline & 9 & 92,50 & 95,83 & 93,75 \\
\hline & 11 & 91,67 & 93,33 & 92,71 \\
\hline \multirow{6}{*}{$30^{\circ}$} & 1 & 93,13 & 92,08 & 94,79 \\
\hline & 3 & 93,54 & 90,42 & 93,75 \\
\hline & 5 & 91,67 & 90,00 & 91,67 \\
\hline & 7 & 92,71 & 92,08 & 93,75 \\
\hline & 9 & 91,67 & 92,08 & 90,63 \\
\hline & 11 & 90,83 & 90,00 & 88,54 \\
\hline \multirow{6}{*}{$45^{\circ}$} & 1 & 92,71 & 96,25 & 95,83 \\
\hline & 3 & 91,25 & 95,42 & 91,67 \\
\hline & 5 & 90,83 & 95,00 & 89,58 \\
\hline & 7 & 92,50 & 96,25 & 93,75 \\
\hline & 9 & 90,00 & 94,58 & 92,71 \\
\hline & 11 & 88,33 & 93,33 & 92,71 \\
\hline
\end{tabular}

Tablo 6. DVM ile düşme ve düşme olmayan eylemlerin sinıflandırılma sonuçları

(Classification results of non-falling and falling actions with SVM)

\begin{tabular}{llll}
\hline Bölge açıs1 & 1. Uygulama & 2.Uygulama & 3.Uygulama \\
\hline $5^{\circ}$ & 95,00 & 97,08 & 97,92 \\
$10^{\circ}$ & 94,37 & 97,08 & 97,92 \\
$30^{\circ}$ & 93,96 & 95,83 & 96,88 \\
$45^{\circ}$ & 93,96 & 97,08 & 95,83 \\
\hline
\end{tabular}

DVM ile düşme ve düşmenin olmadığı (yürüme, eğilme, oturma, çömelme ve uzanma) eylemlerin sinıflandırılmasında birinci uygulamada $5^{\circ}$ lik bölge açısında $\% 95$ oranında, ikinci uygulamada ise $30^{\circ}$ 'lik bölge açısı dişındaki diğer bölge açılarında \%97,08 doğruluk oranında eylem tespiti yapılmıştır. Ayrıca üçüncü uygulamada ise $5^{\circ}, 10^{\circ}$ bölge açılarında $\% 97,92$ doğrulukta düşme eylemi tespiti yapıldığı görülmektedir.

Önerilen yöntemin performans değerlendirmesinin, daha iyi karşılaştırılabilmesi için deneysel çalışmalarda bizler tarafindan hazırlanan veri seti ile birlikte birçok araştırmacı tarafından yaygın olarak kullanılan UTKinect-Action veri seti ile de deneysel çalışmalar yapılmıştır. Bu veri setini kullanan diğer yöntemler ile önerilen yöntemin, veri setindeki 10 eylemin tanınmasındaki ortalama performans karşılaştırması Tablo 7'de görülmektedir.

Tablo 7. UTKinect-Action veri seti ile yapılan çalışmaların performans sonuçları

(Performance results of studies with UTKinect-Action dataset)

\begin{tabular}{llll}
\hline & $\begin{array}{l}\text { Zhu } \\
\text { vd. [32] }\end{array}$ & $\begin{array}{l}\text { Yang } \\
\text { vd. [33] }\end{array}$ & $\begin{array}{l}\text { Önerilen } \\
\text { Yöntem }\end{array}$ \\
\hline Doğruluk & $\% 87,90$ & $\% 88,90$ & $\% 90,03$ \\
\hline
\end{tabular}

Tablo 7'de görüldüğü gibi sırasıyla Zhu vd. çalışmasından yaklaşık \%2 ve Yang vd. çalışmalarından yaklaşık \%1 daha iyi başarıma sahip olduğu görülmektedir. $\mathrm{Bu}$ önerilen yöntemin iskelet verileri kullanılarak eylem tanıma için de etkin bir şekilde kullanılabileceğini göstermektedir.

\section{SONUÇLAR (CONCLUSIONS)}

Bu çalışmada, iskelet verileri kullanılarak özellikle düşme olmak üzere günlük insan eylemlerinin sınıflandırılması yönelik yeni bir yöntem önerilmiştir. Bunun için öncelikle düşme, günlük eylemleri içeren ve FUKinect-Fall olarak adlandırılan yeni bir veri seti oluşturuldu. Önerilen yeni 
yöntemin FUKinect-Fall ile yapılan deneysel çalışmalarında \%97,92 doğrulukta düşme tespiti yapılmıştır. Sadece derinlik görüntüsü ile yapılan çalışmalardan yaklaşık \%4 daha iyi sonuç elde edilmiştir.

Asıl amacımız düşme tespitine yönelik olmasına rağmen mevcut düşme veri setleri içerisinde iskelet verilerinin bulunmaması nedeni ile yöntemin performans değerlendirmesi yapılamamıştır. Önerilen yöntem eylem tanımada iskelet verilerinin yaygın olarak kullanıldığ UTKinect-Action veri seti ile yöntemin performans değerlendirmesi yapılmıştır. Aynı veri ile yapılan çalışmalarda eylem tanımada yaklaşık \%1 daha iyi başarım elde edilmesi yöntemin başarısını kanıtlamaktadır. Ayrıca düşme tespiti üzerine çalışan araştırmacılar için oldukça faydalı olabilecek hem iskelet hem de derinlik verilerini içeren "FUKinect-Fall" veri seti oluşturularak araştırmacıların kullanımına sunulmuştur.

\section{KAYNAKLAR (REFERENCES)}

1. United Nations World Population Ageing 2013. Department of Economic and Social Affairs Population Division.http://www.un.org/en/development/desa/popu lation/publications/pdf/ageing/WorldPopulationAgeing 2013pdf. Yayın tarihi 2013. Erişim tarihi Ocak 5, 2015.

2. Nüfus Projeksiyonlar1 2013-2075.

http://www.tuik.gov.tr/PreHaberBultenleri.do?id=1584 4. Yayı̀n tarihi Şubat 14, 2013. Erişim tarihi Ocak 10, 2015.

3. Fletcher P.C., Hirdes J.P., Risk factors for falling among community-based seniors using home care services, The Journals of Gerontology Series A: Biological Sciences and Medical Sciences, 57 (8), 504-510, 2002.

4. Tinetti M.E., Speechley M., Ginter S.F., Risk factors for falls among elderly persons living in the community, New England journal of medicine, 319 (26), 1701-1707, 1998.

5. Jensen J., Lundin-Olsson L., Nyberg L., Gustafson Y., Falls among frail older people in residential care, Scandinavian Journal of Public Health, 30 (1), 54-61, 2002.

6. Stevens J.A., Rudd R.A., Circumstances and contributing causes of fall deaths among persons aged 65 and older, Journal of the American Geriatrics Society, 62 (3), 470-475, 2014.

7. Wang R.D., Zhang Y.L., Dong L.P., Lu J.W., Zhang Z.Q., He X., Fall detection algorithm for the elderly based on human characteristic matrix and SVM, In Control Automation and Systems (ICCAS), 15th International Conference, Busan-Korea, 1190-1195, 1316 October, 2015.

8. Popoola O.P., Wang K, Video-based abnormal human behavior recognition-A review, IEEE Transactions on Systems Man and Cybernetics Part C Applications and Reviews, 42 (6), 865-878, 2012.

9. Yu H., Zheng X., Zhang L., Cao Y., Elderly fall monitoring and remote assistance system, Jisuanji Gongcheng yu Yingyong (Computer Engineering and Applications), 47 (35), 245-248, 2011.
10. Alwan M., Rajendran P.J., Kell S., Mack D., Dalal S., Wolfe M., Felder R., A smart and passive floorvibration based fall detector for elderly, In Information and Communication Technologies, Damascus-Syria, 1003-1007, 24-26 April, 2006.

11. Rougier C., Meunier J., St-Arnaud A., Rousseau J., Robust video surveillance for fall detection based on human shape deformation, IEEE Transactions on Circuits and Systems for Video Technology, 21 (5), 611-622, 2011.

12. Stone E.E., Skubic M., Fall detection in homes of older adults using the microsoft kinect, IEEE Journal of Biomedical and Health Informatics, 19 (1), 290-301, 2015.

13. Feng W., Liu R., Zhu M., Fall detection for elderly person care in a vision-based home surveillance environment using a monocular camera, Signal Image and Video Processing, 8 (6), 1129-1138, 2014.

14. Bian Z.P., Chau L.P., Magnenat-Thalmann N., Fall detection based on skeleton extraction, Virtual-Reality Continuum and its Applications in Industry, SingaporeSingapore, 91-94, 2-4 December, 2012.

15. Akagündüz E., Aslan M., Şengür A., Wang H., İnce M.C., Silhouette orientation volumes for efficient fall detection in depth videos, IEEE journal of biomedical and health informatics, 21 (3), 756-763, 2017.

16. Ma X., Wang H., Xue B., Zhou M., Ji B., Li Y., Depthbased human fall detection via shape features and improved extreme learning machine, IEEE Journal of Biomedical and Health Informatics, 18 (6), 1915-1922, 2014.

17. Aslan M., Sengur A., Xiao Y., Wang H., Ince M.C., Ma $X$., Shape feature encoding via Fisher Vector for efficient fall detection in depth-videos, Applied Soft Computing, 37, 1023-1028, 2015.

18. Kepski M., Kwolek B., Fall detection using ceilingmounted 3d depth camera, 9th International conference on computer vision and applications (VISAPP), LisbonPortugal, 5-8 January, 640-647, 2014.

19. Dubois A., Charpillet F., Automatic Fall Detection System with a RGB-D Camera using a Hidden Markov Model, 11th International Conference on Smart Homes and Health Telematics (ICOST 2013), SingaporeSingapore, 259-266, 19-21 June, 2013.

20. Zhang C., Tian Y., Rgb-d camera-based daily living activity recognition. Journal of Computer Vision and Image Processing, 2 (4), 1-7, 2012.

21. Akbulut Y., Aslan M., Sengur A., Ince M.C., Fall Detection with Kinect-Based Skeleton Data, International Conference on Natural Science and Engineering (ICNASE'16), Kilis-Turkey, 131-139, 2428 May, 2016.

22. Abhijit Jana. Kinect for Windows SDK Programming Guide. https://www.pdfdrive.net/kinect-for-windowssdk-programming-guide-pdf-e9001088.html. Yayın tarihi Aralık, 2012. Erişim tarihi Ocak 20, 2015.

23. Xia L., Chen C.C., Aggarwal J.K., View invariant human action recognition using histograms of $3 \mathrm{~d}$ joints, 2012 IEEE Computer Society Conference on In 
Computer Vision and Pattern Recognition Workshops (CVPRW), Rhode Isaland-USA, 20-27, 16-21 June, 2012.

24. Chen X., Koskela M., Skeleton-based action recognition with extreme learning machines, Neurocomputing, 149, 387-396, 2015.

25. Chaaraoui A.A., Flórez-Revuelta F., Optimizing human action recognition based on a cooperative coevolutionary algorithm. Engineering Applications of Artificial Intelligence, 31, 116-125, 2014.

26. Shotton J., Sharp T., Kipman A., Fitzgibbon A., Finocchio M., Blake A., Moore R., Real-time human pose recognition in parts from single depth images. Communications of the ACM, 56 (1), 116-124, 2013.

27. Hussein M.E., Torki M., Gowayyed M.A., El-Saban M., Human Action Recognition Using a Temporal Hierarchy of Covariance Descriptors on 3D Joint Locations, Proceedings of the Twenty-Third International Joint Conference on Artificial Intelligence, Beijing-China, 2466-2472, 3-9 Agust, 2013.

28. Fukunaga K., Parametric Classifiers, Introduction to Statistical Patern Recognition, Academic Press Limited,USA, 125-180, 1990.
29. Alcin O.F., Sengur A., Ince M. C., Forward-backward pursuit based sparse extreme learning machine, Journal of The Faculty of Engineering and Architecture of Gazi University, 30 (1), 111-117, 2015.

30. Burges C.J., A tutorial on support vector machines for pattern recognition, Data mining and knowledge discovery, 2 (2), 121-167, 1998.

31. Xia L., Aggarwal J.K., Spatio-temporal depth cuboid similarity feature for activity recognition using depth camera, In Proceedings of the IEEE Conference on Computer Vision and Pattern Recognition, Portland Oregon-USA, 2834-2841, 23-28 June, 2013.

32. Zhu Y., Chen W., Guo G., Fusing spatiotemporal features and joints for $3 \mathrm{~d}$ action recognition. In Proceedings of the IEEE Conference on Computer Vision and Pattern Recognition, Portland Oregon-USA, 486-491, 23-28 June, 2013.

33. Yang X., Tian Y., Super normal vector for activity recognition using depth sequences. In Proceedings of the IEEE Conference on Computer Vision and Pattern Recognition, Columbus OH-USA, 804-811, 23-28 June, 2014. 